\title{
Environmental hazard testing of nanobiomaterials
}

\author{
M. J. B. Amorim ${ }^{*} \mathbb{B}$, M. L. Fernández-Cruz ${ }^{2}$, K. Hund-Rinke ${ }^{3}$ and J. J. Scott-Fordsmand ${ }^{4}$
}

\begin{abstract}
The European Medicines Agency (EMA) regards the potential risks of human medicinal products to the environment and their impacts are assessed, as well as management to limit this impact. Hazard assessment of novel materials, which differ from conventional chemicals, e.g. nanobiomaterials, poses testing challenges and represents a workin-progress with much focus on the optimization of required methodologies. For this work-in-progress, we here highlight where changes/updates are required in relation to the main elements for international testing based on OECD guidelines, supported by knowledge from the nanotoxicity area. The outline describes two major sections, nanobiomaterials and environmental hazards, including its challenges and learned lessons, with recommendations for implementation in OECD guidelines. Finally, the way forward via a testing strategy is described.
\end{abstract}

Keywords: Medical devices, Advanced therapy medicinal products, Nanomedicine, OECD standardization, Nanobiomaterials

\section{Background}

The European Medicines Agency (EMA) defines Nanotechnology "as the use of tiny structures-less than $1000 \mathrm{~nm}$ across - that are designed to have specific properties": this includes mentioning structures and not only substances; the structures are designed on purpose and not just happened to be at nanoscale; the structures have specific properties not obtainable in isolation with the individual components of the nanostructure [1]. This is an example of how specific applications, i.e. medical, may require refined definitions for the same constituent materials. The accuracy of definitions is critical for regulation purposes (see, e.g. the recent guidance for nanoforms [2]) for which materials' regulation depends upon. Regarding the potential environmental risks of human medicinal products, the EMA [3] outlines that "In accordance with Article 8(3) of Directive 2001/83/EC, as amended, the evaluation of the potential environmental risks posed by the use of medicinal products shall be submitted,

\footnotetext{
*Correspondence: mjamorim@ua.pt

${ }^{1}$ Department of Biology and CESAM, University of Aveiro,

3810-193 Aveiro, Portugal

Full list of author information is available at the end of the article
}

their environmental impact shall be assessed and, on a case-by-case basis, specific arrangements to limit this impact shall be considered." There is no legal definition for "nanomedicine" but like for nanomaterials, REACH (Registration, Evaluation, Authorisation and Restriction of Chemicals) [4] or CLP (Classification, Labelling and Packaging) regulations' [5] provisions apply [6].

Nanobiomaterials (NBM) can present a wide array of shapes, forms and status, e.g. powders, fibres, scaffolds, emulsions and the nanoparticles can present different functionalization groups. Hazard assessment of NBM should cover all of materials' life cycle stages, as also discussed for nanomaterials [7]. In the production stage, predominantly human health hazards are envisaged via occupational exposure, whereas when usage/application stage, exposure is mainly to the user (the target in this case). However, all materials may be released during production, and all have an end-of-life and ultimately all go to waste, reaching the environment. Depending on the kind of NBM, emission may be direct or via sewage, for example reaching the environment via wastewater treatment plants, playing a significant role. The diversity of the environment, including atmosphere, aquatic to terrestrial compartments, including a variety of target

\section{Springer Open}

(c) The Author(s) 2020. This article is licensed under a Creative Commons Attribution 4.0 International License, which permits use, sharing, adaptation, distribution and reproduction in any medium or format, as long as you give appropriate credit to the original author(s) and the source, provide a link to the Creative Commons licence, and indicate if changes were made. The images or other third party material in this article are included in the article's Creative Commons licence, unless indicated otherwise in a credit line to the material. If material is not included in the article's Creative Commons licence and your intended use is not permitted by statutory regulation or exceeds the permitted use, you will need to obtain permission directly from the copyright holder. To view a copy of this licence, visit http://creativeco mmons.org/licenses/by/4.0/. 
species and physical chemical factors creates a complex challenge. The terrestrial compartment has been recognized not only as one of the major entry paths but also the sink for NMs [8], e.g. although 90\% CNT (Carbon Nano-Tubes) production is accumulated in landfills it can be discharged depending on the technical design of the dump, $10 \%$ end up directly in soil [9] and less than $1 \%$ is found in sediments and air.

For the development of an intelligent testing strategy (ITS) and integrated risk management (IRM) framework, we need a battery of robust (standardized or validated) ecotoxicity tests. The tests should be fit-for-purpose with the ability to include the test of a variety of novel materials yet to be developed. The aim is to cover realistic worst-case scenarios in a broader sense, to reflect the need for environmental sustainable solutions, and setting increased environmental safety criteria for risk assessment.

We will here go through the general concerns when testing hazard of NBMs. International environmental hazard guidelines follow a general OECD outline and the main elements are selected and discussed (Table 1) (for detailed see Additional file 1):

We describe where changes are required and why, this supported by individual studies methods and results. The outline describes two major sections: (1) nanobiomaterials and (2) environmental hazards, including its challenges, learned lessons and recommendations.

\section{Novel materials: the case of nanobiomaterials (NBM)}

Since an official definition for nanobiomaterials does not exist, we for the purpose of this paper use this term to cover a wide variety of materials. Depending on their use they can be classified as Medical Device (MD) or Advanced Therapy Medicinal Products (ATMP), amongst others. This includes a range of applications, e.g. tissue regeneration, drug delivery, in vivo imaging/biosensing to coating of implants/wounds. Such materials can be provisionally allocated to 1st-generation (Bioinert), 2nd-generation (Bioactive) or 3rd-generation materials (Biomimetic/Bioresorbable/Stimulating specific cellular responses at molecular level) [10] (Additional file 2: Table S1). These cover particulates, fibres and larger scaffold materials; hence, this also covers the variety of forms that will be assessed for potential environmental risks.

\section{Challenges \\ Information on test substance}

The lack of proper characterization equipment and the high dynamic nature of NMs, i.e. transformation, remain the main challenges. Please see ahead "The need

Table 1 Information regarding the main aspects addressed in OECD guidelines, where "NO CHANGE", "CHANGE" or "TO DEVELOP", "TO STANDARDIZE" (partly developed but needs standardization) are recommended for the hazard assessment of NBMs

\begin{tabular}{ll}
\hline Subjects addressed in the OECD environmental in vivo hazard protocols & No change \\
\hline Principle of the test & No change \\
Test acceptance/validity criteria & Change \\
Information on test substance & To develop \\
The need for reference test substances & No change \\
Reference substance-ORGANISMS & To develop \\
Reference substance-MATERIALS & To standardize \\
Description of the test & To develop \\
The need for adaptations to test NBMs & No change \\
The need of instruments and techniques for environmental and biological media characterization & (No)change \\
Preparation of media & Change \\
Selection and preparation of test animals & Change \\
Preparation of test concentrations & To standardize \\
Mixing the test substance to the media-the need for spiking and dispersion consensus & No change \\
Performance of the tests & No change \\
The need of testable materials and worst-case scenarios & Change \\
Test groups and control & Change \\
Test conditions and feeding & Change \\
Test design-The need to cover whole material life cycle and The need of relevant test duration & \\
Treatment of results &
\end{tabular}


of instruments and techniques for environmental and biological media characterisation".

\section{The need for reference test substances}

The need for representative NBMs for testing purposes is very important, also in the context of standardization and validation for regulatory purposes [11]. Depending on the nature of the materials (solid, particulate, fibrous, suspension, etc.) different testing methods are necessary, e.g. testing of nanomaterials requires adaptations to the standard testing methods as developed for chemical substances [12,13]. Whether one reference material (or several) should be recommended to cover these differences is not yet clear. For NMs the European Commission (JRC, Joint Research Center) created a repository for a list of representative NMs [14-16]. What is currently key for environmental safety of NBM is to ensure that such a working list is representative for reference NBMs. This is currently addressed, e.g. in European Union projects such as the H2020: BIORIMA: BIOmaterial RIsk MAnagement. The work focuses on covering a wide variety of materials representing different forms, usages, and potential fate and effect scenarios. The development of references can clearly only progress within an iterative process between scientific evidence and exchange with all involved stakeholders [11]. Further, as well-known, factors such as shelf-life/-stability are important aspects for NMs when it comes to repository reference materials, i.e. less-stable materials will have to be tested within a short time after synthesis. There should be a correspondence between the shelf-life and when actual testing is performed, with a clear indication of the expected time for usage that is fit for purpose.

\section{Description of the test}

\section{The need of instruments and techniques for environmental and biological media characterization}

Characterization, especially in complex media like in solid environmental samples [17], e.g. soil or biological tissues, is not always possible due to difficulties and limitations in the analytical techniques available. This well-known issue hampers the interpretation of results considerably and needs attention.

\section{Performance of the test}

The need of testable materials and worst-case scenarios Materials which cannot be homogeneously distributed in the test media to maximize exposure, e.g. scaffolds, are unsuitable for testing purpose when following the current paradigm for environmental standard hazard guidelines. One of the strategies and main challenge for such materials is the milling for hazard testing purpose. The milling or grinding is recommended to allow testing (e.g. testing impact on small organisms [18]) as this will represent a closer look at a worst-case scenario, i.e. when materials are released in the environment, these undergo ageing, weathering and fragmentation sometimes over many years $[19,20]$. This is especially prominent for NBM, where scaffolds may be composite materials, e.g. polymers with embedded nanomaterials. Even it may seem straightforward to obtain a powdered version of, for example, a bone implant material, it has been shown not to be so because the powder obtained suffers from wide size distribution range or may not represent worst-case nanosize particles. Further, the milling process is often yielding too low amounts compared to testing requirements.

\section{Test design}

The need to cover whole material life cycle Once the material has been fully characterized and the stability known, it must be ensured that all aspects of the materials' full life cycle are covered [21] for the hazard assessment. The form, fate and exposure of each material can differ along the various life cycle stages and at the end of life. This may have a large impact in terms of effect assessment. For instance, a highly durable/persistent material (e.g. like many plastics [22]) may cause little to no toxicity when tested as synthesized/pristine material and using current hazard test systems. However, as the material degrades along the life cycle it may become more reactive, e.g. by releasing embedded compounds or by degradation to smaller particles that are easier taken up, bio-accumulated/-transferred. Such material information should ideally be provided from the materials' producers and the functions and this in turn should be used to derive the best testing strategy.

\section{Learned lessons and recommendations Information on test substance}

The test substance, i.e. test material in this case, should as a minimum contain the information equivalent to what is required in a regulatory context for nanomaterials (see ECHA Annex 6, 7a,b,c [23-25]), e.g. size, shape and surface chemistry. A better approach would be to follow the suggestion by OECD WPMN, see OECD ENV/ $\mathrm{JM} / \mathrm{MONO}(2016) 2$. Obviously only reporting minimum requirements will limit a refined hazard assessment and the possibility to use read-across information.

\section{The need for reference test substances}

To build a repository for representative NBMs, as done for NMs [14], is not trivial and there is a need for many representative materials, i.e. to include the variety of key characteristics. To select one/few representative materials will obviously not capture the potential test limitations. If a set of representative materials is available, then 
it is possible to choose the NBM matching assessing needs.

An example of a successful repository for representative materials are the JRC (Joint Research Centre) representative NMs, i.e. a list of 33 NMs [14]. This has strongly supported test comparison between labs [26], and further supported the analysis of variations within one NM, e.g. $\mathrm{TiO}_{2} \mathrm{NM}$ (NM103, NM104, NM105) [27], without which the guideline update recommendations would not had been possible. The experience from pure nanomaterial science illustrates the problem of representativeness, when it comes to shape and form. For example, a single size or aspect ratio variation in the same particles could mean toxic to non-toxic variations [28]. So in terms of NM representative references, it was important to have both one NM and a suite of different sizes, e.g. custom-designed NMs' libraries [29] and a range of different NMs [30]. Hence, the recommendation is to study a wider range of NBM, as opposed to one or few NBMs, and inspect their potential impacts.

\section{Description of the test}

The need of instruments and techniques for environmental and biological media characterization There is a need to quantify and characterize materials, discriminate between the confounding factors in complex matrices such as the environment or media, including biological tissues. Hence, good methods and instruments need to be developed and made widely available for the research and regulatory community. Although there has been significant progress [31], the techniques and related information from the methods and instruments' developments need to be facilitated also to non-experts. At the same time, given the complexity of the characterization task, efforts and progress made on the measured biological effects (ecotoxicity) should be given higher recognition and weight to support regulation. In essence, if we were to wait with risk assessment until the in situ characterization is fully effective then innovation would be far away.

\section{Performance of the tests}

The need of testable materials and worst-case scenarios Since the NBM come in various shapes, sizes and forms, there is a need to transform these to testable materials to meet the hazard testing requirements. If NBM are solid fibres, discs, bricks etc., we recommend to have these grinded/milled to the nanoscale for hazard testing purpose. We are aware that the approach of grinding the materials, aiming to test a worst-case scenario for the environment, may not capture effects based on the morphology (e.g. aspect ratio dimensions of fibres). The relationship between morphology behaviour and bioavailability has not been investigated and is an additional concern.
For materials with a structural dimension such as scaffolds, a homogeneous distribution in the media and maximization of the exposure can be achieved if the material is grinded to a powder (particles), suitable for spiking directly in solid media or disperse in aqueous media. However, the relevance of these results will be limited unless an ageing of such particles, to represent the full life cycle coverage including end of life.

State-of-the-art standardization hazard procedures foresees mixing of the test material with the test media. Done wrongly this may lead to high unknown variability in exposure concentrations amongst replicates (see "spiking and dispersion issue" below). Further, as pointed out some materials (or primary fragments from these) "may be the same size as or even larger than many important test organisms" this becoming the equivalent of "measuring the toxicity and uptake of rocks from mountains on cows" [18]. Given this, it is important that the grinding or milling is standardized and adequate (nanometer scale), within a small size distribution, i.e. as homogeneous size as possible amongst particles, and provided in sufficient amounts (up-scaling) for hazard testing procedures.

\section{Test design \\ The need to cover whole material life cycle}

It is very important to consider that many of these NBMs are persistent materials, made to last, and will only cause an impact after years of wear and tear or degradation. The biological systems have a limited test duration and even novel longer term testing, e.g. 60 days, will not necessarily capture effects of the material end of life [32]. Hence, test NBMs need to have representative samples from each of the various stages in the full life cycle, e.g. as synthesized, in use, end-of-life [19, 33]. For each step, the shelf-life (persistency/stability) of the sample should be accounted for before testing. To normalize such differences for materials' toxicity ranking (see, e.g. [34]), an ITS should be implemented, namely testing in biological systems based on durability, e.g. (1) highly durable materials shall be tested after ageing and weathering, and (2) highly degradable/changing materials shall be tested as synthesized/pristine. Hence, for very persistent NBMs, we recommend to age and weather these prior exposures in biological systems. The right methodology to obtain such ageing is yet an additional challenge but work is ongoing in this area [21, 35, 36].

\section{Environmental hazard assessment of NBM}

Ecosystem services in a wide environmental diversity should be covered, including functions and species in the terrestrial (bellow and above ground), aquatic and waste water treatment plants. There is currently a range of guidelines that were developed for hazard assessment 
of chemicals, which have been challenged for testing of other materials like nanomaterials (NMs). The present concerns NBMs and its specific characteristics, aiming to cover worst-case scenarios. We hereby summarize the available tools for hazard assessment in the key environmental compartments (soil, water, wastewater treatment plants) and NBM recommended.

\section{Soil: invertebrates}

There are a number of key species with standardized guidelines, which represent a selected start priority to assess novel chemicals and materials see, e.g. REACH. An overview of the most commonly used species in soil is given (Additional file 2: Table S2). Testing should cover as many species as possible, aiming to include representatives of the different life traits and soil functions provided for ecosystem services. Preferentially the number of species should allow for distribution-based approaches (SSD: Species Sensitivity Distribution), and although such an approach may at first seem more costly, it will ensure a much better coverage of major global concerns such as sustainability, including biodiversity, and generally have a benefit (more test results reduce uncertainty). Further, various endpoints should be covered, specially chronic and longer term [37, 38], and besides, bioaccumulation is also of concern for nano-enabled products; hence, trophic transfer is a further issue [39]. As recommended by the European Chemicals Bureau [40], the effect assessment for the terrestrial compartment should include data on (1) primary producers (plants), (2) consumers (e.g. invertebrates that represent an important group in the soil compartment), and (3) decomposers (comprising microorganisms). In this way, spectra should cover various species from different taxonomic groups to ensure a much better coverage of different sensitivity of ecological indicators, e.g. also representing fungivores, herbivores and predators amongst consumers. A wellknown highly relevant aspect is species interactions; this can be assessed using, e.g. multispecies testing systems assembled in the laboratory $[41,42]$ or in higher tier as mesocosms' type [43]. There are several standard guidelines (OECD, ISO) available for soil (Additional file 2: Table S2).

\section{Wastewater treatment plants: microorganisms, including soil microorganisms}

Microorganisms have a key role in terms of degradation and turn-over of many substances and materials. These organisms act as a fully integrated community and the measurement of the impact is on the biological function/ quality (as opposed to effect of individual species).

Waste water treatment plants (WWTPs) are suitable to simulate complex environmental processes in a laboratory scale applying standardized conditions. Originally developed to test the degradability of organic substances, the results of WWTP test show that they can be used to assess the ecotoxicological impact of materials with low or partial degradability. With this WWTP tests, the environmental fate and effect of materials released via sewage can be assessed. Sewage sludge and effluents containing degraded materials can be used in terrestrial and aquatic ecotoxicological tests providing additional information. In contrast to the test design for the approaches with aquatic organisms and soil fauna using single species, populations are used for the assessment of impacts on microorganisms in WWTPS. An overview of selected recommended test guidelines in the scope of registration/notification of chemicals is given (Additional file 2: Table S3). There are many standardized methods [44], an ISO overview is presented by Philippot et al. [45] and an updated version is presented (Additional file 2: Table S4). The methods and results are used as indicators of soil functions [46]. Some approaches and guidelines address one specific microbial function (e.g. ISO 23753-1 (2019); ISO 17155 (2012)) whilst others are designed to address the functional diversity by measuring several functions in one approach (e.g. ISO 20130 (2018); ISO 22939 (2010)). In addition, microbial structural diversity is determined, e.g. common approaches are the analysis of extracted phospholipid fatty acids (PLFA) [47] or of extracted DNA and RNA [48].

\section{Water: algae, invertebrates and vertebrates}

Representative species of three different taxa: algae, invertebrates and vertebrates (fish), should be considered. Further, toxicity varies between species and with water conditions. Hence, the selection of the species should be representative of different scenarios, including freshwater and marine, differences in $\mathrm{pH}$, temperature. There is a number of key species with standardized guidelines to assess hazard in the aquatic compartment. An overview of the most commonly used is given (Additional file 2: Table S5). Although the NBMs are generally not pelagic, there should be a focus on identifying which species and which exposure duration are relevant for particulate exposure scenarios.

\section{Challenges \\ The need for adaptations to test NBM}

The current testing performance paradigm was developed for chemical substances testing, and hence it is not sufficiently adequate for many novel materials, such as NBM. This has been shown for NMs [49] which contain relevant properties needing specific design. For NMs, size is known to be a key distinct feature. Although the hazard assessment and characterization lag far behind 
the materials' technological developments, there are currently available recommendations [26] to reduce the limitations and uncertainty of results obtained with NMs. Recommendations for NBMs should be in line with acquired knowledge from common aspects of NMs.

\section{Description of the test \\ The need for spiking and dispersion consensus}

One of the main challenges relates to well-known and well-characterized exposure during ecotoxicological testing, i.e. the lack of homogeneous dispersions of NBM. Depending on the material's and the environmental media properties, at least two kinds of spiking are recommended, as liquid dispersion and as dry materials. Obviously, both may be used depending on the characteristics that best represent realistic scenarios.

\section{Performance of the test}

\section{Test design and the need of relevant test durations}

It is clear that the standardized test durations and test setup are not adequate for elucidating the importance of many aspects of new materials, e.g. the importance of durability and shapes for the longer term biological effects [50]. Hence, test designs should be adapted to mimic most relevant and up-to-date scenarios, e.g. the test duration should relate to the likely exposure time. From a biological point of view the test design cannot be a one size fits all, but must depend on the test species and endpoint of concern [51].

\section{Learned lessons and recommendations The need for adaptations to test NBMs}

Adaptations of the current guidelines to testing NBM include all referred components to be either integrated or subject to new guidelines/guidance documents as currently done to NMs, please see Table 1 for a list of recommended adaptations. The most important aspects are detailed below.

\section{Description of the test}

\section{The need for spiking and dispersion consensus}

Hazard testing procedures require that the best method is implemented towards a maximum exposure of the biota to the test material. Given the difficulty of mixing solids homogenously into many environments, spiking should be done replicate by replicate. This procedure ensures a known amount of test material in each replicate, which is lost sometimes when first mixed as a stock solution into a batch medium and subsequently split onto replicates. Although the homogeneity of the mixture of the material in the test media cannot be ensured for all materials and media, this technical update improves the reproducibility of amount of material per replicate and hence exposure. Further, the use of electronic microscopy with EDS analyses can help to determine the homogeneity of distribution in various media. The importance of concentration variation within each replicate depends on how much (in time and space) the test organism penetrates the full media core. This methodology can be used for systems where initial disturbance (mixing) is not a problem.

There are also test media-specific issues and recommendations.

Soil media For terrestrial test systems focusing on invertebrates and plants, non-dispersed (dry) NBMs should be mixed as dry constituents prior to soil moistening and before adding the biota [13]. If the test material is a liquid dispersion, it is recommended to add this directly onto pre-moistened soil; further, a control for the liquid without the NBM should be run.

WWTP media For WWTP testing of NBMs materials for which stable stock suspensions can be prepared and which do not sorb significantly to the tubes, stock dispersions should be used. Every WWTP requires a separate vessel with stock dispersions to avoid uneven distribution across replicates. The synthetic sewage, tap water and material's stock dispersion can be mixed within a tube system (concentrated synthetic sewage is mixed with water and then with the test material). In the case a WWTP with denitrification and nitrification chambers being simulated, the mixture is applied into the denitrification section. If a WWTP with just a nitrification chamber is investigated, the mixture is applied into the nitrification section. For materials for which no stable stock suspensions can be prepared, which significantly sorb to the tubes or have other issues, direct addition to each replicate is recommended. The test material can be added directly into the media without making a stock suspension, e.g. denitrification (two-chamber WWTP) or nitrification (one-chamber WWTP) chamber in small amounts at several times per working day (e.g. five times). At the weekend the frequency can be reduced.

For instance, for materials which are primarily released into wastewater and sorb to sewage sludge in wastewater treatment plants the materials can in a test be added to soil as a mixture with sewage sludge, simulating realistic environmental conditions and pathways. Using model wastewater treatment plants for spiking of sewage sludge (OECD Guideline 303A, 2001) considers additionally potential transformations of the material. To measure the impact on terrestrial microorganisms, the treated soil and a control soil are incubated over several weeks and with the microbial activity or the composition of the microbial population is determined at predetermined time-points. 
Aquatic media For aquatic testing [12], dispersions should be directly mixed in the aqueous exposure media. Powders can be dispersed following the NANOGENOTOX protocol [52]. When the previous options are not viable or food exposure is required, administration via food is recommended [53]. An approach for food spiking may be to use water and olive oil as a possible vehicle, although other solvents may be more relevant for various NBMs [54].

\section{Performance of the test}

\section{Test design and the need of relevant test durations}

Concerning the test design and its duration, the two main considerations regard the test organism and the material. The test duration should by default relate to the test species life cycle duration and associated endpoint(s). Nevertheless, most of the standard tests covers only a fraction of the species life cycle, at most only one generation, and favour shorter life cycle species.

We here outline recommendations on adaptations to standard tests illustrating where extension of test duration and optimization of endpoints are possible, circumventing many of the present hurdles of novel materials (see summary in Table 2).

For E. crypticus recommendations are to detail and extend the exposure period as much as practical possible. Regarding detailing, additional detail is possible if using an FLC test instead of an ERT, meaning that a number of endpoints and information can be obtained.

A full life cycle test (46 days, see [57, 61, 62]) represents an added value compared to the standard (28 days). Amongst others, it provides the power to discriminate mechanisms between metal salts and the related metal nanomaterials, and gives an understanding of the sensitive life stages' toxicity. Regarding the extension of the exposure period, e.g. we have beneficial results with monitoring along and up to 84 days instead of 28 days as in the standard guideline. Our results showed that for $E$. crypticus counting (i.e. through additional sampling) the total number of organisms (hence estimating survival and reproduction) at days $0-7-14-21-28-60-84$ allows to observe amplified effects of WCCo NMs at days 60 and 84 , not identified at day 28 [56]. Further, the additional counting at days 7, 14 and 21 provides detection of effects at earlier life stages such as delayed embryogenesis and time to reproduction. Finally, a multigenerational test is optimized [32, 38] and recommended [32, 38], especially to assess the potential epigenetic [37].

For F. candida a multigenerational design is also recommended. Performing a test with an extended exposure period, the density in the test vessels may increase to unpractical numbers, i.e. too high density which would compromise the test viability. Hence, we recommend to perform an extension of the exposure time to 84 days (corresponding to three generations) by restarting of exposure of juveniles after every 28 days, one reproductive cycle $[58,59]$. In addition, the addition of size as an endpoint is recommended to also be included in the test evaluation.

For E. fetida, which has a longer reproductive life cycle (56 days), the recommendation is to favour an added detail in one life cycle, this is instead of the time extension. For example, a full life cycle can be performed where organisms are exposed from the cocoons stage throughout the whole life cycle. This will still require a substantial amount of time and resources for output compared to other smaller species. On the other hand, being a larger species a clear advantage is that it is possible to assess tissue distribution (quantitative) and perform biochemical analysis and further molecular and omics, where the mass of one single worm is enough to perform all analysis. This opens a window for a highly detailed understanding of the mechanism of toxicity, a key feature sought for in novel risks assessment (see also New Approach Methodologies (NAM): Beyond standard testing).

According to OECD TG 216 and 217 (test guidelines on microbial $\mathrm{N}$-transformation and C-transformation) for non-agrochemicals, the incubation period is 28 days. If agrochemicals are tested and the test parameters in treated and control samples differ by more than $25 \%$ on day 28 , the test is continued until a difference equal to or less than $25 \%$ is obtained. The maximum test duration is 100 days. For the effect assessment of NBMs, we propose a general test duration of 100 days, the maximum test duration possible according to the test guidelines. Sampling dates after incubation periods of 7 days, 28 days, 56 days and 84-100 days (corresponding to one, four, eight and 12-14 weeks) are recommended. By the prolonged test duration, delayed bioavailability is considered [63].

For Daphnia magna [64], the standard reproduction test has a duration of 21 days. Multigenerational studies provide a more realistic exposure scenario and offer the opportunity to identify transgenerational effects, not covered by the standard and that may cause significant impact on the population dynamic $[65,66]$. A multigenerational assay includes three generations (F0, F1, F2), each generation is exposed for a period of 21 days, monitoring survival, time of the first brood, and newly born offspring. All the generations may be maintained until the end of their life span (42 days), to test potential differences on the longevity in parental organisms, i.e. a total of 70 days (14 days' sexual maturity F0, 14 days' sexual maturity F1, 42 days' life span of F2). The OECD TG 305 on bioaccumulation in fish 
Table 2 Summary of selected standard tests where highlight is given to potential adaptations FOR THE TESTING OF MANUFACTURED NANOMATERIALS (including nanobiomaterials) of existing OECD/ISO guidelines FOR THE TESTING OF CHEMICALS regarding test duration and endpoints

\begin{tabular}{|c|c|c|}
\hline Test guideline & Test endpoints & Test duration (days) \\
\hline \multicolumn{3}{|l|}{ Enchytraeus crypticus } \\
\hline $\begin{array}{l}\text { Standard (OECD/ISO): } \\
\text { OECD 220; ISO 16386; }\end{array}$ & Survival and Reproduction & $21-28$ \\
\hline OECD 317 & Kinetics : uptake, elimination, BAFs & $14+14$ \\
\hline $\begin{array}{l}\text { Alternative 1: A1 } \\
\text { Full Life Cycle test (adapted from standard [55]) }\end{array}$ & $\begin{array}{l}\text { Hatching } \\
\text { Growth } \\
\text { Maturation } \\
\text { Survival } \\
\text { Reproduction }\end{array}$ & $\begin{array}{l}11 \\
11-46 \\
25 \\
46 \\
46\end{array}$ \\
\hline $\begin{array}{l}\text { Alternative 2: A2 } \\
\text { Extended test (adapted from standard [56]) }\end{array}$ & Survival, Reproduction, Population growth & $\begin{array}{l}7,14,21,28 \\
60,72,84\end{array}$ \\
\hline $\begin{array}{l}\text { Alternative } 3 \text { : A3 } \\
\text { Multigenerational test (adapted from standard } \\
[37,57]) \\
\text { F1-F4 spiked soil + F5-F7 clean soil }\end{array}$ & Survival and reproduction; epigenetics & $32,64,96,128,160,192,224$ \\
\hline $\begin{array}{l}\text { Recommendation: } \\
\text { Use } A 1, A 2, A 3\end{array}$ & All & $46-84$ \\
\hline \multicolumn{3}{|c|}{ Implementation: Add A1, A2 and A3 in OECD/ISO as annexes. } \\
\hline \multicolumn{3}{|c|}{ Folsomia candida } \\
\hline $\begin{array}{l}\text { Standard (OECD/ISO): } \\
\text { OECD 232; } \\
\text { ISO 11267; }\end{array}$ & Survival and Reproduction; & 28 \\
\hline $\begin{array}{l}\text { Alternative 1: B1 } \\
\text { Multigenerational test (adapted from standard } \\
[58,59])\end{array}$ & $\begin{array}{l}\text { F0, F1, F2: Survival, Reproduction, Size (adults, } \\
\text { juveniles) }\end{array}$ & $28,56,84$ \\
\hline Recommendation: Use B1 & All & $28-84$ \\
\hline \multicolumn{3}{|l|}{ Implementation: Add B1 in OECD/ISO as annex } \\
\hline \multicolumn{3}{|l|}{ Eisenia fetida } \\
\hline $\begin{array}{l}\text { Standard (OECD/ISO): } \\
\text { OECD } 222\end{array}$ & $\begin{array}{l}\text { Survival } \\
\text { Reproduction }\end{array}$ & $\begin{array}{l}28 \\
56\end{array}$ \\
\hline OECD 317 & Kinetics: uptake, elimination, BAFs & $21+21$ \\
\hline $\begin{array}{l}\text { Alternative 1: C1 } \\
\text { Full Life Cycle (adapted from standard) }\end{array}$ & $\begin{array}{l}\text { Hatching } \\
\text { Growth } \\
\text { Maturation } \\
\text { Survival } \\
\text { Reproduction }\end{array}$ & $\begin{array}{l}21-28 \\
14,28,42,56 \\
60 \\
14,28,42,56 \\
56\end{array}$ \\
\hline $\begin{array}{l}\text { Alternative 2: } \mathrm{C2} \\
\text { Tissue distribution and biochemical analysis }\end{array}$ & Tissue distribution ${ }^{\mathrm{a}}$ biomarkers, omics & 3-7-14 (flexible) \\
\hline $\begin{array}{l}\text { Recommendation: } \\
\text { Use } \mathrm{C} 1 \text { and } \mathrm{C} 2\end{array}$ & All & $28-84$ \\
\hline \multicolumn{3}{|c|}{$\begin{array}{l}\text { Implementation: Add C1 in OECD/ISO as annex } \\
\text { Make use of C2 and proceed towards standardization } \\
\text { Use A1-A3 as surrogate (oligochaete with shorter life cycle) }\end{array}$} \\
\hline $\begin{array}{l}\text { Alternative } 3: C 3 \\
\text { Earthworm in vitro test [60] }\end{array}$ & $\begin{array}{l}\text { Cell viability—biomarkers, omics, corona forma- } \\
\text { tion }\end{array}$ & 1 \\
\hline $\begin{array}{l}\text { Recommendation: } \\
\text { Use C } 3 \text { for rapid mode-of-action understanding }\end{array}$ & All & 1 \\
\hline \multicolumn{3}{|c|}{ Implementation: Further develop this system to a higher TRL level } \\
\hline \multicolumn{3}{|c|}{ Microorganisms } \\
\hline $\begin{array}{l}\text { Standard (OECD/ISO): } \\
\text { OECD 216/ISO 14238 }\end{array}$ & N-Transformation & $28-100$ \\
\hline $\begin{array}{l}\text { Standard (OECD/ISO): } \\
\text { OECD 217/ISO } 14239\end{array}$ & C-Transformation & $28-100$ \\
\hline $\begin{array}{l}\text { Alternative } 1: \mathrm{D} 1 \\
\text { Fixed prolonged test duration }\end{array}$ & All microbial activities & $84-100$ \\
\hline
\end{tabular}


Table 2 (continued)

\begin{tabular}{|c|c|c|}
\hline Test guideline & Test endpoints & Test duration (days) \\
\hline $\begin{array}{l}\text { Alternative 2: D2 } \\
\text { ISO } 15685\end{array}$ & Potential ammonium oxidation & $84-100$ \\
\hline Recommendation: Use D1 and D2 & All & $84-100$ \\
\hline \multicolumn{3}{|c|}{$\begin{array}{l}\text { Implementation: Add D1 in OECD/ISO as annex for particular materials } \\
\text { Add D2 in guidance for the testing of toxic ion releasing particular materials }\end{array}$} \\
\hline $\begin{array}{l}\text { Standard (OECD/ISO): } \\
\text { OECD } 303 \mathrm{~A}\end{array}$ & C-Transformation, N-Transformation & No fixed duration (plateau phase of min. 21 days) \\
\hline $\begin{array}{l}\text { Alternative } 1: \text { E1 } \\
\text { Addition of denitrification chamber }\end{array}$ & $\begin{array}{l}\text { C-Transformation, N-Transformation; sewage } \\
\text { sludge for soil spiking }\end{array}$ & $\begin{array}{l}\text { Transformation: no fixed duration } \\
\text { Spiking: } 10 \text { days (mean sludge age in a wastewa- } \\
\text { ter treatment plant) }\end{array}$ \\
\hline Recommendation: Use E1 & $\begin{array}{l}\text { C-Transformation, N-Transformation; sewage } \\
\text { sludge for soil spiking }\end{array}$ & $\begin{array}{l}\text { Transformation: no fixed duration } \\
\text { Spiking: } 10 \text { days (mean sludge age in a wastewa- } \\
\text { ter treatment plant) }\end{array}$ \\
\hline \multicolumn{3}{|c|}{ Implementation: Add E1 in OECD as annex for particular material } \\
\hline \multicolumn{3}{|l|}{ Daphnia magna } \\
\hline $\begin{array}{l}\text { Standard (OECD/ISO): } \\
\text { OECD TG211 } \\
\text { ISO } 10706\end{array}$ & $\begin{array}{l}\text { Survival } \\
\text { Reproduction } \\
\text { Growth (length) }\end{array}$ & 21 (daily monitoring) \\
\hline $\begin{array}{l}\text { Alternative 1: } F 1 \\
\text { Multigenerational }(F 0, F 1, F 2)\end{array}$ & $\begin{array}{l}\text { Survival } \\
\text { Reproduction } \\
\text { Growth (length) }\end{array}$ & $21,42,70$ \\
\hline Recommendation: Use F1 & All & 70 \\
\hline \multicolumn{3}{|c|}{ Implementation: Add F1 as annex to OECD TG211 } \\
\hline \multicolumn{3}{|c|}{ Fish } \\
\hline $\begin{array}{l}\text { Standard (OECD/ISO): } \\
\text { OECD TG305 }\end{array}$ & Bioaccumulation & Dietary: $(10-14)+28$ or 42 \\
\hline Alternative 1: G1 & Bioaccumulation & Dietary: $(10-14)+52$ or more \\
\hline Recommendation: Use G1 & All & depuration period of 52 or more days \\
\hline Implementation: Add G1 as annex tc & & \\
\hline
\end{tabular}

a Instrument and method that allows quantification of the specific material are required

includes two exposure alternatives, aqueous media for soluble substances or dietary for non-soluble substances. For NBMs, a dietary exposure will be the most appropriate, meaning an uptake of 7-14 days and postexposure (depuration) for up to 28 or 42 days, i.e. until the test substance can no longer be quantified in whole fish (OECD 2012b). According to previous experiments with $\mathrm{ZnO}$ NMs [67] depuration was not fully achieved in intestine and gills, hence larger periods of depuration should be considered and are expected needed for certain NBMs.

As detailed above there are many lessons learned from research in ecotoxicity of NMs, especially that more long-term information regarding hazard should be provided. As described, such information can be achieved in various ways, the most obvious options are by extending the test duration and by testing aged/weathered materials [21], whilst obtaining more detailed information, e.g. as additional endpoints.

\section{Way forward: a testing strategy Mode of action: Standard testing in a strategic tiered approach}

The Hazard Assessment (HA) should comprise identification of the biological target (e.g. estimated specific endpoints or species affected) and the identification of the magnitude of the related biological response (e.g. estimated via a concentration-response analysis). If a biological mechanism is known for the NBM, then this should be considered in the choice of test systems, for example some materials are designed to be anti-microbial and this should prioritize microbial testing and the closest network associate in the trophic chain, e.g. microbialdependent organisms. If specific concern exists based on NBMs' transformation, e.g. partial transformation at anaerobic/aerobic conditions then the duration of the transformation should guide how long test durations are chosen. If a route to the environment is through WWTP and sorption of NBM to sewage sludge is expected, then 
sewage sludge tests are recommended. In various EU countries the sewage sludge is used as fertilizer and NBM can be released into the terrestrial compartment via this route. The simulation of WWTPs and the testing of sewage sludge added to soil are suitable as a higher tier approach in case of a specific concern. This is of course especially important to consider for NBM used in MD and ATMPs since these often have prior known target and function.

Despite the intelligent choice of testing based on materials' characteristics and intended purpose, this is not standalone, because many human health-targeted materials (designed for a specific mode of action) can cause collateral or unintended environmental damage.

\section{Long-term exposure testing-adapting standard testing}

As outlined above, test adaptations in regard to exposure duration for NBMs are still ongoing. However, it is clearly shown that by prolonging the test duration and detailing the sampling points, it is possible to identify effects not caught in the standard testing and also to identify especially sensitive life stages. Hence, an HA that takes into account long-term effects and added detailed endpoint series offers many advantages and is preferred for Risk Assessment (RA). In case of materials with potential long-term effects due to the resulting forms after ageing, long-term tests could better tackle hazards and avoid future claim for damages, this representing a clear advantage for the producer to go beyond the regulatory requirements, saving costs at a longer term perspective, but most importantly to increase safety for the environment.

\section{New approach methodologies (NAM): beyond standard} testing

Hazard identification evaluates the ecotoxicological data from a range of relevant species to assess the intrinsic hazard of a substance. Current ecotoxicological approaches to assess hazards of NBMs can either be based on methods adopted from classical ecotoxicology (OECD/ISO guidelines) or New Approach Methodologies (NAM) [68] including, e.g. mechanistic endpoints [69]. New Approach Methodologies usually refer to alternative methods, such as in silico and in vitro methods and may also include modelling, read-across and system biological outputs. These approaches can provide fundamental molecular-mechanistic understanding of the related toxicity, an aspect not caught in the classical regulatory ecotoxicology. This should obviously also be pursued for NBMs, with the additional benefit here that such approaches may also help to make the NBMs more effective in regard to their use, besides making them less of an environmental hazard. Assessments using NAM can be used both in relation to ECHA (European Chemicals Agency) and to TSCA (The Toxic Substance Control Act, US). For the environment, there are alternative models and endpoints, beyond OECD and ISO, which cover many relevant aspects and that fill in gaps of standard testing, especially for novel materials like NBM, and also that support the integration of omics as alternative tools for risk assessment [70]. Amorim et al. [69] show an overview of available tests in the terrestrial compartment and levels of detail that can be obtained (Additional file 2: Table S6).

Depending on the goal the Hazard Assessment strategy could proceed as a tiered approach (for a proposal see Fig. 1) moving from screening at the phenotypic organism level: (1) individual species chronic tests, to (2) individual species extended chronic tests; individual species multigenerational test, and add (3) multispecies extended test. The choice of test level will depend on the realistic worst-case scenario based on detailed evaluation of material properties. For an understanding of the underlying mechanisms of action screen at the non-phenotypical sub-organism level: (1) individual species cell viability assessment and multi-endpoint (in vitro short-term exposure), (2) multispecies in vitro tests (high-throughput multi-endpoint) and (3) omics. One
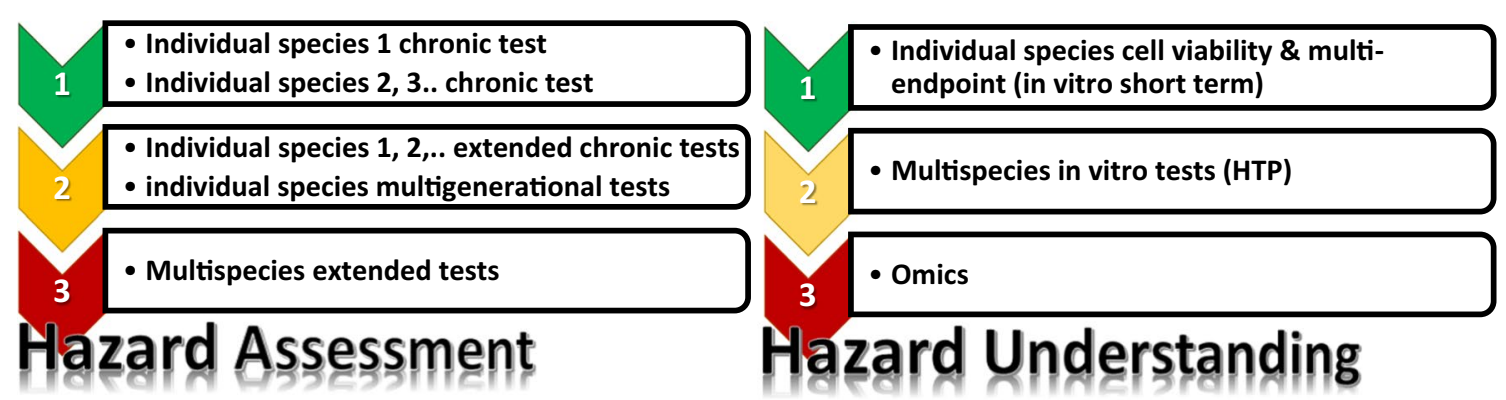

Fig. 1 Schematic representation for a tiered hazard assessment (left panel) framework; alternative and additional testing towards "hazard understanding" is outlined (right panel) 
example of such full coverage for the standard test species Enchytraeus crypticus has been performed for a $\mathrm{Cu}$ NMs' case study, showing the striking understanding obtained from combining in vitro testing [60], all omics (transcriptomics [71], metabolomics [72], proteomics [73]), epigenetics [37], full life cycle [57], full life span [50], multigenerational [38] and multispecies test system $[41,42]$. Hazard understanding will not only fulfil the scientific community requirement for a better understanding of the world, but it will also serve as the basis and rational for regulators to decide upon the need for modifications of the current procedures for the testing of materials' hazards.

Many of the described gaps in relation to NBMs come from the infancy of the NBMs' research field compared to conventional chemicals and even to pure NMs. On the other hand, we are far ahead in terms of information access, knowledge and technology than the previous pioneer fellows [74], hence hold far larger responsibility to ensure not only the sustainability for future generations but also to make it a better world.

\section{Supplementary information}

Supplementary information accompanies this paper at https://doi. org/10.1186/s12302-020-00369-8.

Additional file 1. Additional information regarding the subjects addressed in the OECD environmental in-vivo hazard protocols.

Additional file 2: Table S1. Representative bionanomaterials list types. Table S2. Overview of key terrestrial species and standard guidelines. Table S3. Overview of key microbial activity standard guidelines. Table S4. ISO Standard methods available in soil microbiology. Table S5. Overview of key aquatic species and standard guidelines. Table S6. Overview of available tests for effect assessment for soil invertebrates.

\section{Abbreviations}

ATMP: Advanced therapy medicinal products; BIORIMA: BIOmaterial RIsk MAnagement; CLP: Classification, labelling and packaging; ECHA: European Chemicals Agency; EMA: European Medicines Agency; EMEA: European Medicines Evaluation Agency; HA: Hazard assessment; IRM: Integrated risk management; ITS: Intelligent testing strategy; ISO: International standard organization; JRC: Joint Research Center; NAM: New approach methodologies; NBM: Nanobiomaterials; NM: Nanomaterial; OECD: Organization for Economic Cooperation and Development; REACH: Registration, Evaluation, Authorisation and Restriction of Chemicals; TG: Technical guidance; TSCA: The Toxic Substance Control Act; WWTPs: Waste water treatment plants.

\section{Acknowledgements}

Not applicable.

\section{Authors' contributions}

MJBA drafted the first version of the manuscript, KHR, MLF, and JSF were responsible for specific sections. All authors read and approved the final manuscript.

\section{Funding}

This study was supported by the European Commission Project H2020NMBP-2017 BIORIMA: BIOmaterial Risk MAnagement (GA No. 760928). Further support within H2020-NMBP-TO-IND-2018 NANORIGO: Establishing a NANOtechnology RIsk Governance Framework (GA No. 814530) and CESAM [UIDB
/50017/2020 + UIDP/50017/2020], to FCT/MEC through national funds, and the co-funding by the FEDER, within the PT2020 Partnership Agreement and Compete 2020.

Availability of data and materials

Not applicable.

Ethics approval and consent to participate

Not applicable.

\section{Consent for publication}

Not applicable.

\section{Competing interests}

The authors declare that they have no competing interests.

\section{Author details}

${ }^{1}$ Department of Biology and CESAM, University of Aveiro, 3810-193 Aveiro, Portugal. ${ }^{2}$ Department of Environment and Agronomy, National Institute for Agricultural and Food Research and Technology (INIA), Ctra. de la Coruna Km 7.5, 28040 Madrid, Spain. ${ }^{3}$ Fraunhofer Institute for Molecular Biology and Applied Ecology IME, Auf dem Aberg 1, 57392 Schmallenberg, Germany. ${ }^{4}$ Department of Bioscience, Aarhus University, Vejlsoevej 25, 8600 Silkeborg, Denmark.

Received: 6 April 2020 Accepted: 15 June 2020

Published online: 21 July 2020

\section{References}

1. Pita R, Ehmann F, Papaluca M (2016) Nanomedicines in the EU-regulatory overview. AAPS J 18:1576-1582. https://doi.org/10.1208/s1224 8-016-9967-1

2. ECHA (2019) Appendix for nanoforms applicable to the Guidance on Registration and substance identification

3. EMA (2018) Guideline on the environmental risk assessment of medicinal products for human use. Eur Med Agency 44:1-12

4. European Commission (EC) (2006) Regulation No 1907/2006 of the European Parliament and of the Council of 18 December 2006 concerning the Registration, Evaluation, Authorisation and Restriction of Chemicals $(\mathrm{REACH})$, establishing a European Chemicals Agency, amending Directive 1999/45/EC

5. European Commission (EC) (2008) Regulation No 1272/2008 of the European Parliament and of the Council of 16 December 2008 on classification, labelling and packaging of substances and mixtures, amending and repealing Directives 67/548/EEC and 1999/45/EC, and amending Regulation (EC) No 1

6. ECHA (2011) Guidance on information requirements and chemical safety assessment Chapter R.2: Framework for generation of information on intrinsic properties

7. OECD (2015) Series on the Safety of Manufactured Nanomaterials No. 57: Guidance manual towards the integration of risk assessment into life cycle assessment of nano-enabled applications

8. Sun TY, Bornhöft NA, Hungerbühler K, Nowack B (2016) Dynamic probabilistic modeling of environmental emissions of engineered nanomaterials. Environ Sci Technol 50:4701-4711. https://doi.org/10.1021/acs. est.5b05828

9. Bundschuh M, Filser J, Lüderwald S et al (2018) Nanoparticles in the environment: where do we come from, where do we go to? Environ Sci Eur. https://doi.org/10.1186/s12302-018-0132-6

10. Hench LL, Thompson I (2010) Twenty-first century challenges for biomaterials. J R Soc Interface 7:S379-\$391

11. Halamoda-Kenzaoui B, Holzwarth U, Roebben G et al (2018) Mapping of the available standards against the regulatory needs for nanomedicines. Wiley Interdiscip Rev Nanomed Nanobiotechnol 11:e1531. https://doi. org/10.1002/wnan.1531

12. OECD (2017) Dispersion stability of nanomaterials in simulated environmental media. Oecd Guidel Test Chem. https://doi.org/10.1787/97892 64067394-eng 
13. OECD (2012) Organisation for economic cooperation and development. Guidance on sample preparation and dosimetry for the safety testing of manufactured nanomaterials. Series Safety Manufact Nanomater 36:1-16

14. EC (2016) European Commission Joint Research Centre JRC nanomaterials repository list of representative nanomaterials

15. Klein CL, Comero S, Stahlmecke B et al (2011) NM-series of representative manufactured nanomaterials, NM-300 silver characterisation, stability, homogeneity. Publications Office of the European Union, Luxembourg

16. Rasmussen K, Mast J, Temmerman P-J De, et al (2014) Titanium dioxide, NM-100, NM-101, NM-102, NM-103, NM-104, NM-105: characterisation and physico- chemical properties. JRC repository: NM-series of representative manufactured nanomaterials. European Commission. Ispra, Italy

17. Navratilova J, Praetorius A, Gondikas A et al (2015) Detection of engineered copper nanoparticles in soil using single particle ICP-MS. Int J Environ Res Public Health 12:15756-15768. https://doi.org/10.3390/ijerp h121215020

18. Scott-Fordsmand JJ, Navas JM, Hund-Rinke K et al (2017) Nanomaterials to microplastics: swings and roundabouts. Nano Today 17:7-10. https:// doi.org/10.1016/j.nantod.2017.09.002

19. Amorim MJB, Lin S, Schlich K et al (2018) Environmental impacts by fragments released from nanoenabled products: a multiassay, multimaterial exploration by the SUN approach. Environ Sci Technol 52:1514-1524. https://doi.org/10.1021/acs.est.7b04122

20. Neubauer N, Scifo L, Navratilova J et al (2017) Nanoscale coloristic pigments: upper limits on releases from pigmented plastic during environmental aging, in food contact, and by leaching. Environ Sci Technol 51:11669-11680. https://doi.org/10.1021/acs.est.7b02578

21. Nowack B, Boldrin A, Caballero A et al (2016) Meeting the needs for released nanomaterials required for further testing-The SUN approach. Environ Sci Technol 50:2747-2753. https://doi.org/10.1021/acs.est.5b044 72

22. Kawecki D, Nowack B (2019) Polymer-specific modeling of the environmental emissions of seven commodity plastics as macro- and microplastics. Environ Sci Technol 53:9664-9676. https://doi.org/10.1021/acs. est.9b02900

23. ECHA (2017) Appendix R7-1 for nanomaterials applicable to Chapter R7b Endpoint specific guidance. 1-13. https://doi.org/10.2823/647499

24. ECHA (2017) Appendix R. 6-1 : Recommendations for nanomaterials applicable to the Guidance on QSARs and Grouping. 29. https://doi. org $/ 10.2823 / 884050$

25. ECHA (2017) Appendix R7-1 for nanomaterials applicable to Chapter R7a (Endpoint specific guidance) Guidance on information requirements and chemical safety assessment Appendix R7-1 for nanomaterials applicable to Chapter R7a Endpoint specific guidance Appendix R7-1 f

26. Hund-Rinke K, Baun A, Cupi D et al (2016) Regulatory ecotoxicity testing of nanomaterials - proposed modifications of OECD test guidelines based on laboratory experience with silver and titanium dioxide nanoparticles. Nanotoxicology 10:1442-1447. https://doi.org/10.1080/17435 390.2016.1229517

27. Gomes SIL, Roca CP, von der Kammer F et al (2018) Mechanisms of (photo)toxicity of $\mathrm{TiO}_{2}$ nanomaterials (NM103, NM104, NM105): using high-throughput gene expression in Enchytraeus crypticus. Nanoscale 10:21960-21970. https://doi.org/10.1039/C8NR03251C

28. Naatz H, Lin S, Li R et al (2017) Safe-by-design of CuO nanoparticles via Fe-doping, $\mathrm{Cu}-\mathrm{O}$ bond lengths variation, and biological assessment in cells and zebrafish embryos. ACS Nano 11:501-515. https://doi. org/10.1016/j.coviro.2015.09.001.Human

29. Pokhrel S, Nel AE, Mädler L (2013) Custom-designed nanomaterial libraries for testing metal oxide toxicity. Acc Chem Res 46:632-641. https://doi. org/10.1021/ar300032q

30. Puzyn T, Rasulev B, Gajewicz A et al (2011) Using nano-QSAR to predict the cytotoxicity of metal oxide nanoparticles. Nat Nanotechnol 6:175-178. https://doi.org/10.1038/nnano.2011.10

31. Praetorius A, Gundlach-Graham A, Goldberg E et al (2017) Single-particle multi-element fingerprinting (spMEF) using inductively-coupled plasma time-of-flight mass spectrometry (ICP-TOFMS) to identify engineered nanoparticles against the elevated natural background in soils. Environ Sci Nano 4:307-314

32. Ribeiro MJ, Scott-Fordsmand JJ, Amorim MJB (2019) Multigenerational exposure to cobalt (CoCl2) and WCCo nanoparticles in Enchytraeus crypticus. Nanotoxicology. https://doi.org/10.1080/17435390.2019.1570374
33. Mitrano DM, Nowack B (2017) The need for a life-cycle based aging paradigm for nanomaterials: importance of real-world test systems to identify realistic particle transformations. Nanotechnology 28:072001. https://doi. org/10.1088/1361-6528/28/7/072001

34. Scott-Fordsmand JJ, Amorim MJB, Sørensen PB (2018) Implementing the DF4 in a robust model, allowing for enhanced comparison, prioritisation and grouping of Nanomaterials. Regul Toxicol Pharmacol 92:207-212. https://doi.org/10.1016/j.yrtph.2017.12.008

35. Bressot C, Manier N, Pagnoux C et al (2017) Environmental release of engineered nanomaterials from commercial tiles under standardized abrasion conditions. J Hazard Mater 322:276-283. https://doi. org/10.1016/j.jhazmat.2016.05.039

36. Tiwary CS, Kishore S, Vasireddi R et al (2017) Electronic waste recycling via cryo-milling and nanoparticle beneficiation. Mater Today 20:67-73. https ://doi.org/10.1016/j.mattod.2017.01.015

37. Bicho RC, Roelofs D, Mariën J et al (2020) Epigenetic effects of (nano) materials in environmental species-Cu case study in Enchytraeus crypticus. Environ Int 136:105447. https://doi.org/10.1016/j.envint.2019.105447

38. Bicho R, Santos F, Scott-Fordsmand J, Amorim M (2017) Multigenerational effects of copper nanomaterials (CuONMs) are different of those of CuCl2: exposure in the soil invertebrate Enchytraeus crypticus. Sci Rep 7:1-7. https://doi.org/10.1038/s41598-017-08911-0

39. Petersen E, Mortimer M, Burgess RM et al (2019) Strategies for robust and accurate experimental approaches to quantify nanomaterial bioaccumulation across a broad range of organisms. Environ Sci Nano. https://doi. org/10.1039/C8EN01378K

40. European Chemicals Bureau (2003) Thecnical Guidance Document on Risk Assessment Part II

41. Mendes LA, Amorim MJB, Scott-Fordsmand JJ (2019) Assessing the toxicity of safer by design $\mathrm{CuO}$ surface-modifications using terrestrial multispecies assays. Sci Total Environ 678:457-465. https://doi.org/10.1016/j. scitotenv.2019.04.444

42. Mendes LA, Amorim MJB, Scott-Fordsmand JJ (2018) Interactions of soil species exposed to CuO NMs are different from Cu salt: a multispecies test. Environ Sci Technol 52:4413-4421. https://doi.org/10.1021/acs. est.8b00535

43. Jänsch S, Frampton GK, Römbke J et al (2006) Effects of pesticides on soil invertebrates in model ecosystem and field studies: a review and comparison with laboratory toxicity data. Environ Toxicol Chem 25:2490-2501

44. Römbke J, Bernard J, Martin-Laurent F (2018) Standard methods for the assessment of structural and functional diversity of soil organisms: a review. Integr Environ Assess Manag 14:463-479. https://doi.org/10.1002/ ieam.4046

45. Philippot L, Ritz K, Pandard P et al (2012) Standardisation of methods in soil microbiology: progress and challenges. FEMS Microbiol Ecol 82:1-10. https://doi.org/10.1111/j.1574-6941.2012.01436.x

46. Nannipieri P, Giagnoni L, Renella G et al (2012) Soil enzymology: classical and molecular approaches. Biol Fertil Soils 48:743-762. https://doi. org/10.1007/s00374-012-0723-0

47. Xu C, Peng C, Sun L et al (2015) Distinctive effects of TiO2 and CuO nanoparticles on soil microbes and their community structures in flooded paddy soil. Soil Biol Biochem 86:24-33

48. Hund-Rinke K, Hümmler A, Schlinkert R et al (2019) Evaluation of microbial shifts caused by a silver nanomaterial: comparison of four test systems. Environ Sci Eur 31:1-13. https://doi.org/10.1186/s12302-019-0268-z

49. EP (2009) European parliament resolution of 24 April 2009 on regulatory aspects of nanomaterials. Eur. Parliam. 2208:1-10

50. Gonçalves MFM, Gomes SIL, Scott-Fordsmand JJ, Amorim MJB (2017) Shorter lifetime of a soil invertebrate species when exposed to copper oxide nanoparticles in a full lifespan exposure test. Sci Rep 7:1-8. https:// doi.org/10.1038/s41598-017-01507-8

51. Santos FCF, Gomes SIL, Scott-Fordsmand JJ, Amorim MJB (2017) Hazard assessment of nickel nanoparticles in soil-The use of a full life cycle test with Enchytraeus crypticus. Environ Toxicol Chem 36:2934-2941. https:// doi.org/10.1002/etc.3853

52. Jensen $K$, Kembouche $Y$, Christiansen E, et al (2011) The generic NANOGENOTOX dispersion protocol. In: Jensen K, Thieret N (eds) Standard Operation Procedure (SOP) and background documentation Final Protocol for producing suitable manufactured nanomaterial exposure media

53. OECD (2012) Guidelines for the Testing of Chemicals No. 305. Bioaccumulation in fish: aqueous and dietary exposure 
54. OECD (2019) Draft—Guidance document on aquatic and sediment toxicological testing of nanomaterials

55. Bicho RC, Santos FCF, Gonçalves MFM et al (2015) Enchytraeid Reproduction TestPLUS: hatching, growth and full life cycle test-an optional multi-endpoint test with Enchytraeus crypticus. Ecotoxicology. https:// doi.org/10.1007/s10646-015-1445-5

56. Ribeiro MJ, Maria VL, Soares AMVM et al (2018) Fate and Effect of Nano Tungsten Carbide Cobalt (WCCo) in the Soil Environment: observing a Nanoparticle Specific Toxicity in Enchytraeus crypticus. Environ Sci Technol 52:11394-11401. https://doi.org/10.1021/acs.est.8b02537

57. Bicho R, Santos F, Scott-Fordsmand J, Amorim M (2017) Effects of copper oxide nanomaterials (CuONMs) are life stage dependent_full life cycle in Enchytraeus crypticus. Environ Pollut 224:117-124. https://doi. org/10.1016/j.envpol.2017.01.067

58. Guimarães B, Maria VL, Römbke J, Amorim MJB (2019) Multigenerational exposure of Folsomia candida to ivermectin-using avoidance, survival, reproduction, size and cellular markers as endpoints. Geoderma 337:273-279. https://doi.org/10.1016/j.geoderma.2018.09.030

59. Guimarães B, Maria VL, Römbke J, Amorim MJB (2018) Exposure of Folsomia candida (Willem 1902) to teflubenzuron over three generations Increase of toxicity in the third generation. Appl Soil Ecol 134:8-14. https ://doi.org/10.1016/j.apsoil.2018.10.003

60. Ribeiro MJ, Amorim MJB, Scott-Fordsmand JJ (2019) Cell in vitro testing with soil invertebrates_-challenges and opportunities toward modeling the effect of nanomaterials: a surface-modified CuO case study. Nanomaterials 9:1087. https://doi.org/10.3390/nano9081087

61. Bicho R, Santos F, Goncalves M et al (2015) Enchytraeid Reproduction Test(PLUS): hatching, growth and full life cycle test-an optional multiendpoint test with Enchytraeus crypticus. Ecotoxicology 24:1053-1063. https://doi.org/10.1007/s10646-015-1445-5

62. Bicho RC, Ribeiro T, Rodrigues NP et al (2016) Effects of Ag nanomaterials (NM300K) and Ag salt (AgNO3) can be discriminated in a full life cycle long term test with Enchytraeus crypticus. J Hazard Mater 318:608-614. https://doi.org/10.1016/j.jhazmat.2016.07.040

63. Schlich K, Klawonn T, Terytze K, Hund-Rinke K (2013) Hazard assessment of a silver nanoparticle in soil applied via sewage sludge. Environ Sci Eur 25:1-14. https://doi.org/10.1186/2190-4715-25-17

64. OECD (2012) OECD guidelines for testing of chemicals - daphnia magna reproduction test (No. 211)
65. Hartmann S, Louch R, Zeumer R et al (2019) Comparative multi-generation study on long-term effects of pristine and wastewater-borne silver and titanium dioxide nanoparticles on key lifecycle parameters in Daphnia magna. Nanoimpact. https://doi.org/10.1016/j.impact.2019.100163

66. Völker C, Boedicker C et al (2013) Comparative toxicity assessment of nanosilver on three daphnia species in acute, Chronic and Multi-Generation Experiments. PLoS ONE 8:e75026. https://doi.org/10.1371/journ al.pone.0075026

67. Connolly M, Fernández M, Onde E et al (2016) Tissue distribution of zinc and subtle oxidative stress effects after dietary administration of $\mathrm{ZnO}$ nanoparticles to rainbow trout. Sci Total Environ 551-552:334-343. https ://doi.org/10.1016/j.scitotenv.2016.01.186

68. ECHA (European Chemicals Agency) (2016) New Approach Methodologies in Regulatory Science

69. Amorim MJB, Roca CP, Scott-Fordsmand JJ (2016) Effect assessment of engineered nanoparticles in solid media_current insight and the way forward. Environ Pollut 218:1370-1375. https://doi.org/10.1016/j.envpo I.2015.08.048

70. Guilera J, Aguilera-Gomez M, Barrucci F et al (2018) EFSA Scientific Colloquium 24 -'omics in risk assessment: state of the art and next steps. EFSA Support Publ 15:1-30. https://doi.org/10.2903/sp.efsa.2018.EN-1512

71. Gomes SIL, Roca CP, Pegoraro N et al (2018) High-throughput tool to discriminate effects of NMs (Cu-NPs, Cu-nanowires, CuNO3, and Cu salt aged): transcriptomics in Enchytraeus crypticus. Nanotoxicology 12:325-340. https://doi.org/10.1080/17435390.2018.1446559

72. Maria VL, Licha D, Ranninger C et al (2018) The Enchytraeus crypticus stress metabolome-CuO NM case study. Nanotoxicology 12:766-780. https:// doi.org/10.1080/17435390.2018.1481237

73. Maria VL, Licha D, Scott-Fordsmand JJ et al (2018) The Proteome of Enchytraeus crypticus - exposure to CuO nanomaterial and $\mathrm{CuCl} 2$ - in pursue of a mechanistic interpretation. Proteomics 18:1-6. https://doi. org/10.1002/pmic.201800091

74. Carson R (1962) Silent spring. Houghton Mifflin, United States

\section{Publisher's Note}

Springer Nature remains neutral with regard to jurisdictional claims in published maps and institutional affiliations.

\section{Submit your manuscript to a SpringerOpen ${ }^{\circ}$ journal and benefit from:}

- Convenient online submission

- Rigorous peer review

- Open access: articles freely available online

- High visibility within the field

- Retaining the copyright to your article

Submit your next manuscript at $\boldsymbol{\nabla}$ springeropen.com 